1984

\title{
Poverty, Inequality, and City Homicide Rates: Some Not So Unexpected Findings
}

\author{
William C. Bailey \\ Cleveland State University, w.bailey@csuohio.edu
}

Follow this and additional works at: https://engagedscholarship.csuohio.edu/clsoc_crim_facpub

Part of the Criminology Commons

How does access to this work benefit you? Let us know!

\section{Original Citation}

Bailey W. C. (1984), Poverty, inequality, and city homicide rates. Criminology, 22(4), 531-550. doi: 10.1111/j.1745-9125.1984.tb00314.x

\section{Repository Citation}

Bailey, William C., "Poverty, Inequality, and City Homicide Rates: Some Not So Unexpected Findings" (1984). Sociology \& Criminology Faculty Publications. 31.

https://engagedscholarship.csuohio.edu/clsoc_crim_facpub/31

This Article is brought to you for free and open access by the Sociology \& Criminology Department at EngagedScholarship@CSU. It has been accepted for inclusion in Sociology \& Criminology Faculty Publications by an authorized administrator of EngagedScholarship@CSU. For more information, please contact library.es@csuohio.edu. 
Messner's recent investigation of homicide and relative and absolute economic deprivation is replicated here, but cities rather than SMSA's and three years $(1950,1960,1970)$ rather than one (1970) are considered. Because of tremendous intra-unit variation for SMSAs with respect to homicides and sociodemographic characteristics (an important variation that is masked when data are aggregated on a SMSA level), cities are a preferable unit of analysis in cross-sectional investigations of homicide. Where Messner found a significant negative relationship between percentage of poverty (absolute deprivation) and homicides, I consistently find the opposite pattern as predicted. In both studies, however, there is only a slight and nonsignificant relationship between relative economic deprivation (income inequality) and homicides. Unlike Messner, however, I do not consider this finding surprising. At best, there is only a weak theoretical linkage between homicide and relative economic deprivation. Accordingly, the results of this investigation for both absolute and relative deprivation are neither "perplexing" nor do they warrant the "serious reconsideration of the linkages between poverty, inequality and the homicide rate" that Messner (1982: 112) calls for.

\title{
Poverty, Inequality, and City Homicide Rates
}

\author{
Some Not So Unexpected Findings
}

\author{
WILLIAM C. BAILEY \\ Cleveland State University
}

In a recent article Stephen Messner (1982: 105) examines: "Whether the [homicide] crime rate is better predicted by measures of poverty corresponding to the relative approach or by measures reflecting the subsistence approach." That is, is homicide better understood as a response to relative or absolute deprivation as measured by some fixed standard of well-being?

For Messner this is an important but neglected theoretical question. There is a long tradition linking poverty conceptualized in "absolute terms" with crime, including violent crime. At the 
extremes, such arguments have ranged from posing social disorganization (Shaw and McKay, 1942) to posing the inherent propensities of the poor (Banfield, 1968, 1974) as explaining the poverty-crime relation. On the other hand, relative deprivation has also long occupied an important position in various accounts of crime and delinquency (Merton, 1938; Henry and Short, 1954; Cohen, 1955; Cloward and Ohlin, 1960), and this conceptualization of deprivation is pivotal in a number of current explanations of crime in Western societies (Merton, 1968; Quinney, 1970, 1974, 1975, 1980; Gordon, 1971; Chambliss and Seidman, 1982; Taylor et al., 1973; Kreisberg, 1975; Reasons and Rich, 1978).

\section{MESSNER'S TEST OF THE DEPRIVATION QUESTION}

To examine the effect of "absolute" and "relative" deprivation on homicide, Messner incorporated a measure of each and five control factors (population, population density, percentage of black population, percentage of population 15-29 years of age, and a region/south dummy variable) into a cross-sectional analysis of 204 SMSAs where crime data are available in the $1970 \mathrm{FBI}$ Uniform Crime Reports. When the Gini coefficient of income inequality and percentage of the population below the U.S. Social Security Administration's poverty line were considered simultaneously, the findings were contrary to expectations. Relative deprivation (Gini) was only slightly associated with homicides ( $\mathrm{F}$ $=1.775$ ) and percentage of poverty was significantly but negatively associated with killings $(\mathrm{F}=6.609, \mathrm{p}<.05)$.

To test whether these surprising results were due to collinearity between income inequality and poverty $(r=.81)$, Messner considered each measure of deprivation individually. Again, there was only a chance relation between income inequality and homicides $(F=.354)$, and a significant $(\mathrm{p}<.05)$ but negative relationship between percentage of poverty and killings $(F=$ 5.178). Throughout the analyses there was a significant and positive association between homicides and percentage of black, region, population, and population density.

Surprised by these findings, Messner speculated that possibly the Social Security Administration's poverty line is "too high" for identifying those at risk to homicide (109). To test this question, percentage of families with annual incomes of less than $\$ 1,000$ 
was substituted for percentage of poverty and the analysis was repeated. Again the results were opposite than expected. Percentage of low income was significantly $(p<.01)$ but negatively related to homicides $(\mathrm{F}=7.391)$.

\section{MESSNER'S EXPLANATION OF HIS FINDINGS}

Messner finds these negative findings "perplexing," but he offers several possible explanations: (1) The range of income inequality across SMSAs $\left[\mathrm{X}=.34, \mathrm{~s} . \mathrm{d}_{\mathrm{d}}=.03\right]$ may be too restricted to assess its effect on homicides; (2) the Gini index of inequality may not provide an accurate indicator of relative deprivation; (3) SMSAs may not serve as a relevant frame of reference in assessing economic well-being; (4) relative economic deprivation may not be an important determinant of criminal homicide; (5) regarding poverty, he says, "perhaps widespread poverty somehow reduces the probability that any given poor person will commit homicidal acts. .. . Widespread poverty might actually entail less objective deprivation insofar as such poverty increases the likelihood that poor people will voluntarily share the limited economic resources that they do have" (1982: 112). Messner gives credence to only the fourth of these explanations, and concludes that his findings call for a "serious reconsideration of the linkages between poverty, inequality and the homicide rate" (1982: 112).

\section{MESSNER'S FINDINGS AND PREVIOUS RESEARCH}

Indeed, both Messner's findings and his conclusion that his study requires a serious reconsideration of the theoretical linkages between poverty, inequality and homicide are "perplexing." A careful reading suggests that it is his findings and conclusions that are in need of reconsideration. First, there is a long line of studies of social areas within communities and crosssectional studies of cities and states that show a direct and significant relation between poverty and other indicators of poor economic conditions and homicide (Schmid, 1960; Schuessler, 19611962; Schuessler and Slatin, 1964; Quinney, 1966; Boggs, 1965; Monkonnen, 1975; McCarthy et al., 1975; Choldin, 1976; Humphries and Wallace, 1980). Similarly, there are a number of in- 
depth analyses that show a clear link between low economic status and homicide (Brearly, 1932; Bullock, 1955; Wolfgang, 1958; Bensing and Schroeder, 1960; Pokorny, 1965; MacDonald, 1961; Lundsgaarde, 1977; Curtis, 1974; Block 1977). This is an impressive body of research and is clearly not called into question by a single study (Messner, 1982). In addition, there are also a handful of cross-sectional studies (that do not simultaneously consider poverty) that report a direct relation between income inequality, or some other form of relative deprivation, and homicide that cannot be easily dismissed (Loftin and Hill, 1974; Mathur, 1978; Blau and Blau, 1982). ${ }^{2}$

\section{SMSAs AS UNITS OF ANALYSIS}

Directly pertaining to Messner's study, serious questions can be raised about considering Standard Metropolitan Statistical Areas (SMSAs) as a unit of analysis is examining the relation between homicide and poverty or income inequality. SMSAs are typically bound by county lines and are far from homogeneous "social communities" with respect to crime and sociodemographic characteristics as Messner claims (1982: 106). Homicide rates are much higher in central cities within SMSAs than in surrounding areas. For example, for the 204 SMSAs Messner considers for 1970 , the mean homicide rate is 7.10 per 100,000 population. This compares to a rate of 10.0 for cities in the $100,000-250,000$ range, 14.7 for those between 250,000 and $500,000,18.4$ for those 500,000 to 1 million in number, and 17.5 for cities over 1 million population (FBI, 1971: 104). Unfortunately, this important variation in intra-SMSA homicides is masked when rates are computed on the basis of the total number of murders in an SMSA (most of which often lies outside the central city) or the population of the SMSA (most of which often lies outside the central city) and when the ratio of the city population to the SMSA population varies tremendously from one SMSA to another. To illustrate, for SMSAs in 1970 with inner-city populations of 100,000 or more, $56 \%$ of the population resided outside the city (range $=5$ to $90 \%$ ) but $69 \%$ of the homicides took place in the inner city (range $=21$ to $97 \%$ ).

Similarly, SMSAs are quite diverse sociodemographically. For the 204 SMSAs Messner considered in 1970, 9.8\% of the total 
population was black, $9.8 \%$ of the population fell below the poverty line, and the average Gini coefficient was .34. In contrast, in SMSAs having a city with a population of 100,000 or more an average of $17.3 \%$ of the city population was black, $10.4 \%$ of families were below the poverty line, and the average Gini value was .38. The average Gini of .38 for cities is similar to the mean of .34 for SMSAs, but variation in income inequality is much greater between cities (.208 to .505) than SMSAs (.308 to .410).

In sum, on sheer mathematical grounds there is no reason that SMSAs cannot be the units of observation in computing crime rates and sociodemographic measures. However, aggregation at the SMSA level has the effect of ignoring theoretically important variation in homicides and other factors of interest within the SMSA. But such variation clearly does exist. ${ }^{3}$

In addition, I share Messner's (1982: 112) concern about whether SMSAs provide "relevant frames of reference in the assessment of economic well-being" and relative deprivation. It may be that daily associations and experiences are more salient in assessing one's economic well-being relative to others than a self assessment based on a "generalized other" at the county (SMSA) level. Thus, although the Gini index may provide a reasonable measure of relative deprivation it might be preferable to compute such a measure on the basis of less highly aggregated social/demographic units, such as cities.

\section{THE PRESENT INVESTIGATION}

The present investigation is both a replication and an extension of Messner's analysis, using U.S. cities as the units of analysis. As noted, cities are much more homogeneous than SMSAs and by considering them we avoid the aggregation problems discussed above. ${ }^{4}$ In addition, cities are and long have been major centers of homicides in this country. Importantly, however, homicide rates are not uniformly high for large cities. Rates vary considerably, with cities like Cleveland, Newark, Atlanta, and Detroit having over 30 homicides per 100,000 population in 1970 and cities like Milwaukee, San Diego, Rochester, Sacramento, and St. Paul having rates below the national average (7.8). It is this important inter-city variation in homicides that is of concern in this analysis. 


\section{METHODS AND PROCEDURES}

To test the effect of relative and absolute deprivation on homicides, I employed the same procedures and models used by Messner. For all cities with a 1970 population of 100,000 or more $(\mathrm{n}=153)$, figures for murder and nonnegligent manslaughter were drawn from the Uniform Crime Reports $(1971)^{5}$ and the required data for each of the sociodemographic variables were drawn from Bureau of Census publications. These variables are as follows:

(1) percentage of population below the U.S. Social Security Administration's poverty line-a measure of absolute deprivation

(2) the Gini index of income inequality-a measure of relative deprivation

(3) percentage of families with an annual income below $\$ 1,000-$ a measure of low income

(4) percentage of black population

(5) percentage of population 15-29 years of age

(6) a southern regional dummy (0/1) variable

(7) population

(8) population density

Because of the highly skewed (nonnormally distributed) nature of the 1970 homicide, population, and population density data (Ott, 1977:626-627), natural log transformations were performed on these variables.

To extend the analysis beyond a single year (1970), comparable figures were gathered for 1950 and 1960 . Because poverty data are available for 1960 only for cities within SMSAs with a population of 250,000 or more, it is only possible to compare the effect of absolute versus relative deprivation on homicides for this year for a reduced number $(n=73)$ of larger cities. It is possible, however, to examine the relation between homicide and income inequality and percentage of low income for all jurisidictions $(n=$ 138) for which offense data are available in the 1960 Uniform Crime Reports. Poverty data are not available for cities for 1950 because this year predates the development of a national poverty index. But low income (less than $\$ 1,000$ ) data, the Gini index, and homicide data are available for a large majority $(n=137)$ of the sample cities. Accordingly, it is possible for 1950 to consider low income as one measure of absolute deprivation and income inequality as a measure of relative deprivation. As with 1970 the 
population and population density figures are seriously skewed for 1960 and 1950 and $\log$ transformations were performed. In contrast to 1970, the homicide data for these two years are not so skewed as to require transformation.

\section{RESULTS}

Relative vs. Absolute

Economic Deprivation

If there is merit to the absolute and relative deprivation arguments, we would expect a significant positive relation between homcides and the three measures of economic disadvantage. At the bivariate level, this pattern holds for each of the three time periods. There is a moderate and positive relation between murder rates and relative deprivation $(1970=.471,1960=.562$, $1950=.525)$, low income $(1970=.621,1960=.741,1950=.581)$, and percentage of poverty $(1970=.648,1960=.755)$ for the two years for which poverty data are available. ${ }^{6}$

These bivariate results for cities are consistent in direction with Messner's findings for SMSAs, but he reports a less substantial positive relation between 1970 murder rates and income inequality $(r=.44)$ and percentage of poverty $(r=.29)$. Messner does not report the bivariate relation between percentage of low income and murder rates. ${ }^{7}$

To determine the relative effect of absolute and relative deprivation on killings, both types of measures must be considered simultaneously. In testing this question Messner considered percentage of poverty, the Gini index of income inequality (and five control variables), and 1970 SMSA homicide rates in a multiple regression. Table 1 reports the results of the same analysis for 1960 and 1970, using cities as the unit of observation.

Whereas Messner found a significant inverse relation between poverty (absolute deprivation) and murder rates for SMSAs, for cities these two factors are positively and significantly associated as predicted. Like Messner, however, I found a positive, but only a chance, relation between income inequality (relative deprivation) and murder.

Trying to account for the inconsistent findings for both relative and absolute deprivation, Messner questions whether income inequality and pecentage of poverty are too collinear $(r=$ 
.81) to include in the same regression. As there is a fairly substantial relation between these two factors for cities as well, $(1970=$ $.639,1960=.683)$, I followed his procedure of considering each measure of inequality separately.

Table 2 reports regression results when income inequality (the Gini index) is excluded from the model. This analysis also shows a significant positive relation between percentage of poverty and homicides. For 1960 , poverty is the best predictor of killings, and it has the second largest beta value for 1970 of the six variables considered.

To assess whether the negative results for income inequality are due to a suppressor effect caused by the inclusion of percentage of poverty in the analysis (Table 1), I considered solely income inequality as a measure of economic deprivation in Table 3.

Again there is no support for the relative deprivation argument. As before (Table 1), there is a positive, but only a chance, relation between income inequality and homicide rates for 1970 and 1960 , and a very slight and negative association between these two factors for 1950. For 1970 and 1960, the F-ratios for income inequality are larger than their counterparts in Table 1 $(1970=3.153$ versus $.707 ; 1960=2.397$ versus .033$)$, but this is expected as percentage of poverty and income inequality are not independent factors for either year. By excluding percentage of

TABLE 1

Regression Results Using Percentage of Poverty and Income Inequality as Predictors of Murder Rates

\begin{tabular}{lccccc}
\hline & \multicolumn{2}{c}{1970} & & \multicolumn{2}{c}{1960} \\
\cline { 2 - 3 } \cline { 6 - 7 } $\begin{array}{l}\text { Independent } \\
\text { Variable }\end{array}$ & Beta/R & F-Ratio & & Beta/ $\mathbf{R}^{2}$ & F-Ratio \\
\hline Percentage Black & .490 & $41.235 \mathrm{c}$ & & .327 & $9.005 \mathrm{~b}$ \\
South & .129 & .073 & & .234 & 2.639 \\
Log Population & .217 & $16.122 \mathrm{c}$ & & .016 & .043 \\
Log Density & -.006 & .009 & & -.008 & .007 \\
Percentage 15-29 yrs. & -.114 & $4.922 \mathrm{a}$ & & .001 & .000 \\
Percentage Poverty & .196 & $5.427 \mathrm{a}$ & & .357 & $7.299 \mathrm{~b}$ \\
Income Inequality & .059 & .707 & & .021 & .033 \\
\multicolumn{1}{c}{$\mathbf{R}^{2}$} & .648 & $37.352 \mathrm{c}$ & & .676 & $19.437 \mathrm{c}$ \\
\hline
\end{tabular}

$a=p<.05 ; b=p<.01 ; c=p<.001$. 
TABLE 2

Regression Results Using Percentage of Poverty as a Predictor of Murder Rates

\begin{tabular}{lccccc}
\hline & \multicolumn{2}{c}{1970} & & \multicolumn{2}{c}{1960} \\
\cline { 2 - 3 } \cline { 6 - 6 } $\begin{array}{l}\text { Independent } \\
\text { Variable }\end{array}$ & Beta/ $\mathbf{R}^{2}$ & F-Ratio & & Beta/R & F-Ratio \\
\hline Percentage Black & .489 & $41.226 \mathrm{c}$ & & .336 & $10.540 \mathrm{~b}$ \\
South & .092 & 1.724 & & .245 & 3.207 \\
Log Population & .223 & $17.187 \mathrm{c}$ & & .013 & .027 \\
Log Density & -.001 & .000 & & -.001 & .000 \\
Percentage 15-29 yrs. & -.106 & $4.354 \mathrm{a}$ & & .022 & .087 \\
Percentage Poverty & .222 & $7.988 \mathrm{~b}$ & .355 & $7.652 \mathrm{~b}$ \\
\multicolumn{1}{c}{$\mathrm{R}^{2}$} & .646 & $43.549 \mathrm{c}$ & & .680 & $23.363 \mathrm{~b}$ \\
\hline
\end{tabular}

$a=p<.05 ; b=p<.01 ; c=p<.001$.

poverty from the regression, however, it is clear from Table 3 that the negative findings for income inequality (Tables 1 and 3) are not due to collinearity between measures of absolute and relative deprivation.

In addition, the negative results for income inequality are not due to its collinearity with the other variables in the model presented in Table 3. When income inequality is regressed against the five sociodemographic factors considered, a significant $(\mathrm{p}<.001) \mathrm{R}^{2}$ results for each year: $1970=.409 ; 1960=.439$; $1950=.487$. Importantly, however, neither individually nor in linear combination are the sociodemographic factors so closely associated with income inequality that they cannot be considered as predictors in the same regression. Rather, for each year the $R^{2}$ value indicates that a majority of the variation in income inequality is not a function of any or all of the sociodemographic variables.

Low Income as a Measure of Absolute Deprivation

In contrast to our results, Messner found a significant negative relation between percentage of poverty and murder rates. $\mathrm{He}$ 
TABLE 3

Regression Results Using Income Inequality

as a Predictor of Murder Rates

\begin{tabular}{|c|c|c|c|c|c|c|}
\hline \multirow{2}{*}{$\begin{array}{l}\text { Independent } \\
\text { Variable }\end{array}$} & \multicolumn{2}{|c|}{1970} & \multicolumn{2}{|c|}{1960} & \multicolumn{2}{|c|}{1950} \\
\hline & Beta/ $\mathbf{R}^{2}$ & F-Ratio & Bata/ $\mathbf{R}^{2}$ & F-Ratio & Beta/ $\mathbf{R}^{2}$ & F-Ratio \\
\hline Percentage Black & .587 & $82.294 c$ & .423 & $32.609 c$ & .441 & $29.138 \mathrm{c}$ \\
\hline South & .111 & 2.337 & .374 & $16.285 c$ & .405 & $18.814 c$ \\
\hline Log Population & .213 & $15.081 \mathrm{c}$ & .037 & .367 & .075 & 1.435 \\
\hline Log Density & -.010 & .026 & -.004 & .004 & -.054 & .707 \\
\hline Percentage $15-29$ yrs. & -.112 & $4.642 a$ & -.093 & 2.702 & .040 & .480 \\
\hline Income Inequality & .117 & 3.153 & .117 & 2.397 & -.006 & .007 \\
\hline $\mathrm{R}^{2}$ & .634 & $41.390 c$ & .610 & $34.382 c$ & .643 & $38.988 c$ \\
\hline
\end{tabular}

$a=p<.05 ; b=p<.01 ; c=p<.001$.

speculates that this may be because the official poverty line is "too high" for identifying those at risk to homicide. When he substituted a low-income/poverty measure-proportion of families with annual incomes below $\$ 1000$-and reestimated his model, the results were also "perplexing." Like percentage of poverty, low income and murder rates were negatively and significantly $(\mathrm{p}<.01)$ associated.

To test whether this unexpected finding may also be an artifact of considering SMSAs, Table 4 reports a replication of Messner's low-income analysis for cities.

For two of the three years there is general support for the absolute deprivation argument. For 1960, percentage of low income and murder are positively and significantly associated, and the F-ratio for low income for $1970(F=3.365)$ is fairly close to that required $(F=3.92)$ at the .05 level of significance. In contrast, there is only a slight positive relation between these two factors for 1950 , but this may be due to the way that the low income variable is operationalized. For 1970 and 1960, families with incomes below $\$ 1000$ may well be considered economically deprived in an absolute sense, with this level being only $10.1 \%$ and $17.8 \%$ of the national median family income for these two years, respectively. In contrast, for $1950 \$ 1000$ was about one-third (33.2\%) of the national median family income and, therefore, did not constitute such a low level of subsistence. Accordingly, using a $\$ 1000$ cutting point may be questionable as a measure of low income for 1950 compared to 1960 and 1970 . The only alternative 
TABLE 4

Regression Results Using Percentage of Low Income as a Predictor of Murder Rates

\begin{tabular}{|c|c|c|c|c|c|c|}
\hline \multirow{2}{*}{$\begin{array}{l}\text { Independent } \\
\text { Variable }\end{array}$} & \multicolumn{2}{|c|}{1970} & \multicolumn{2}{|c|}{1960} & \multicolumn{2}{|c|}{1950} \\
\hline & Beta/R ${ }^{2}$ & F-Ratio & Beta/R $\mathbf{R}^{2}$ & F-Patio & Beta/ $/ R^{2}$ & F-Ratio \\
\hline Percentage Black & .533 & $47.639 c$ & .395 & $27.054 c$ & .402 & $19.912 c$ \\
\hline South & .129 & 3.508 & .347 & $14.148 c$ & .383 & $19.798 c$ \\
\hline Log Population & .215 & $15.375 c$ & .042 & .478 & .086 & 1.837 \\
\hline Log Density & -.010 & .025 & -.034 & .242 & -.057 & .785 \\
\hline Percentage $15-29$ yrs. & -.112 & $4.657 a$ & -.095 & 2.880 & .052 & .774 \\
\hline Percentage Low Income & .143 & 3.365 & .168 & $4.412 a$ & .071 & .865 \\
\hline$R^{2}$ & .635 & $41.486 c$ & .617 & $35.502 c$ & .645 & $39.388 \mathrm{c}$ \\
\hline
\end{tabular}

$a=p<.05 ; b=p<.01 ; c=p<.001$.

that is possible with the available 1950 census data is to enumerate families with annual incomes below $\$ 500$, but this would seem an unrealistically low cutting point compared to $\$ 1000$ for 1960 and 1970.

\section{Results for the}

Control Variables

So far sole attention has been paid to the deprivation variables, but the results for some of the control variables are also of theoretical interest. They also provide some contrasts with Messner's findings. First, one of the best predictors of city homicide rates is percentage of black population (pecentage of nonwhite population for 1960 and 1950), and this holds throughout the analysis when income inequality (Tables 1 and 3), poverty (Tables 1 and 2 ), and low income (Table 4) are held constant. This pattern is consistent for all three time periods and suggests that minority status has an independent effect on killings that is not simply a function of economic disadvantage, at least as measured here.

Second, higher murder rates in the South have long been attributed to a "southern tradition/culture of violence" (Brearley, 1932; Franklin, 1956; Hackney, 1969; Gastil, 1971; Magura, 1975). However, some critics have contended that these higher rates are merely a function of higher levels of economic deprivation and/or a larger black population in this region (Loftin and Hill, 1974; Allen and Bankston, 1981; Allen et al., 1981; Smith 
and Parker, 1980; Parker and Smith, 1979; Humphries and Wallace, 1980).

Our findings for U.S. cities are at odds with the "southern culture of violence" argument whereas Messner claims that a southern regional effect on homicides "appears unmistakably in the [his] regression analyses" (1982: 111). When both poverty and income inequality are controlled (Table 1), there is only a chance relation between region and homicides for 1960 and 1970 . When income inequality is excluded from the analysis (Table 2) this pattern is unaltered. But when percentage of poverty is excluded (Table 3), southern cities have significantly higher homicide rates for 1960 , but not for 1970 . These findings are to be expected because of the closer relation between poverty and region for $1960(r=.807)$ than for the latter decade $(1970, r=.563)$, which showed both a narrowing of the gap in general economic development and a reduction in the homicide differential between the South and other regions of the country (Hackney, 1969; Jacobson, 1975). Unfortunately, it is not possible to examine the effect of region on homicides controlling for both poverty and income inequality for 1950 due to the lack of an adequate index of the former type of deprivation. ${ }^{8}$

A third control variable of interest is population size. At the bivariate level $(r=.414)$ and in the regression analysis, population size is a significant $(\mathrm{p}<.001)$ predictor of homicides for 1970 . This finding is consistent with classic (Simmel, 1903; Wirth, 1938) and more recent arguments that in large macrostructures such as major cities, the "superficial" and "transitory" nature of social relations contributes to higher rates of criminal violence (Mayhew and Levinger, 1976: 86). But why does this pattern not hold for 1950 and 1960 ?

At the bivariate level, city population and homicides are only slightly associated for $1960(\mathrm{r}=.053)$ and $1950(.012)$, and these weak associations are not a result of a suppressor effect caused by any of the sociodemographic variables considered. (Rather, Tables 1-4 show only a chance partial relation between these two factors.) Nor do the inconsistent results for 1950 and 1960 seem to be a function of a restricted distribution of the population variable for the two earlier years. This is indicated both by the standard deviations and by the mean-to-standard deviation ratios for the log population variable $(1950 ; \overline{\mathrm{X}}=12.08$, s.d. $=.94$ : $1960 ; \bar{X}=12.71$, s.d. $=.82: 1970 ; \bar{X}=12.33$, s.d. $=.79$ ). 
In short, there is indeed a pattern of higher homicide rates in larger cities for 1970 , but this may relfect the impact of some other (unknown) factor(s), and not the effect of population size per se. Accordingly, we find no support for Mayhew and Levinger's (1976: 86) contention "that taking population size explicitly into account" enhances "the explanatory power of sociological theories" of homicide and relative and absolute deprivation.

Finally, neither this analysis nor Messner's indicates that age structure has a direct effect on urban lethal violence. In both his and my analysis percentage of population 15-29 years of age is negatively associated with 1970 homicide rates, and slightly positively associated with rates for 1960 and 1950 . These findings are not consistent with the claim that there should be a significant reduction in crime as young people grow out of the "at risk" years (President's Committee on Law Enforcement and the Administration of Justice, 1967; Sagi and Wellford, 1968; Ferdinand, 1970; Wellford, 1973). This hope may be reasonable for some offenses, but the determinants of murder seem rooted in much less transitory factors than simple shifts in age composition.

\section{SUMMARY AND CONCLUSIONS}

In this article I have provided a replication and an extension of Stephen Messner's recent analysis of relative and absolute economic deprivation and homicide rates for 1970 . To his surprise, Messner found that neither absolute deprivation (percentage of poverty) nor relative deprivation (the Gini index) were significant predictors of homicides. On the contrary, there was virtually no association between income inequality and offense rates and there was a significant negative association between poverty, an alternative low-income variable, and murder. Messner repeatedly labels these findings as "perplexing," but feels confident enough in his analysis to call for a serious reconsideration of the theoretical tradition in criminology linking poverty, inequality, and homicides.

I also find his results surprising, but I think they hardly call for the theoretical soul-searching that he feels his study justifies. In large part this analysis suggests that his overall negative findings may simply be a result of his choice of questionable units of observation-Standard Metropolitan Statistical Areas. Crime and the required sociodemographic data are readily available for 
SMSAs, but they are highly questionable units to consider because of intra-SMSA variation in homicides and the sociodemographic factors of interest. When the required data are aggregated on a SMSA level, theoretically important variation in both the predictor and dependent variables is treated as nonexistent. To do this is to commit a serious error, which helps to explain Messner's "perplexing" findings.

The results of this study of cities rather than SMSAs, and for three time periods rather than one (1970), do not "call for a serious reconsideration of the linkages between poverty, inequality, and the homicide rate." Rather, I consistently find that poverty and homicide rates are positively and significantly associated (1970 and 1960) as the theoretical literature predicts. Accordingly, I see no need whatsoever to call into question the assumption that poverty-conceptualized here and by Messner as absolute economic deprivation-is an important determinant of homicide.

However, like Messner, I find no evidence that income inequalityhis and my measure of relative deprivation-is a significant contributor to homicides. Moreover, even the slight and insignificant relation between these two factors (Table 3) would appear to be a function of the association between poverty and income inequality. When both deprivation variables are considered simultaneously (Table 1), the homicide-inequality relation becomes weaker and does not differ from zero statistically. Unlike Messner, however, I do not consider these findings for income inequality terribly surprising.

Messner is correct in stating that over the last decade there has been a move by social scientists to conceptualize economic hardship and deprivation more in relative than absolute/fixed terms. $\mathrm{He}$ is also correct in stating that relative economic deprivation is an important theroretical notion in contemporary criminology. $\mathrm{He}$ is incorrect, however, in assuming that there is a strong theoretical "linkage" in criminology between relative economic deprivation and murder. Rather, from the early writings of Engles (1968) and Bonger (1916) through various statements of Merton's anomie thesis $(1938,1968)$ to current Marxist and neoMarxist analyses, it is primarily property crimes and not crimes of violence that are seen as resulting from relative economic deprivation. Take, for example, Merton's classic notion of "inno- 
vation" (crime) as a mode of response to anomie. Nowhere in the anomie theory does Merton develop a firm link between relative economic deprivation and murder, which typically has little to do with material/economic gain (Luckenbill, 1977). At best, he simply notes in a brief response to Cohen (1955) that crime and delinquency need not be utilitarian in a material/economic sense (1968: 231-232), but even here Merton is extremely vague about the type of nonutilitarian offenses covered by his theory (Clinard, 1964: 19). In fact, nowhere in this discussion does Merton mention homicide or any other violent offense.

Similarly, there is no clear thesis in the traditional or more recent Marxist and neo-Marxist literature linking disparities in income to homicides, which commonly result from disputes between family members, friends, lovers, or persons otherwise known to one another. Quinney (1980: 61), for example, is not specific about this matter, only arguing that personal crimes (murder, assault, and rape) are perpetrated by those "brutalized by the conditions of capitalism" and that "these actions occur in immediate situations that are themselves the result of more basic accommodations to capitalism."

Only in the most general terms have people such as Coser (1963), in discussing the larger issue of violence and social conditions, posed a possible link between economic inequality and homicide. That possible link is as follows: (1) Economic inequality may or may not be perceived as unjust by lower-status persons; (2) perceived economic inequality may result in frustration and possible aggression by low-status persons; (3) aggression resulting from such frustration may be directed against oneself, repressed or sublimated, or channeled outward in a directed or nondirected manner; (4) homicide may be the result of outwardly directed aggression; (5) rates will be particularly high for categories of persons who experience disproportionately "structurally induced frustrations," and for those in strata where "internalized social controls are not strong enough to prevent... homicidal aggression"-the poor, blacks, persons raised in broken homes, and so on (Coser, 1963).

On the most elementary level Coser's proposed link between inequality and homicide seems plausible but, obviously, many contingencies remain to be specified in his now 20-year-old analysis. Accordingly, it may be that an adequate test of the relative 
economic deprivation argument for homicide requires a more sophisticated analysis than the simple inclusion of a conventional measure of income inequality (the Gini index) in an additive model of city offense rates. Or it may be that a dimension of economic inequality other than income or a more inclusive multidimensional conceptualization of economic inequality is required to provide an adequate test of the relative deprivationhomicide question. Conversely, however, it may simply be that relative economic deprivation is not an important determinant of either the rate of violent interpersonal conflicts or the probability that they will have a lethal outcome. This analysis clearly does not rule this out as a distinct possibility as income inequality is a fundamental dimension of economic inequality in this society.

\section{NOTES}

1. This is, indeed, an interesting conclusion for Messner to reach as in a recent investigation (Messner, 1980) he draws just the opposite conclusion about homicide and income inequality. He reports a significant positive relation between these two factors when considering 39 nations, and he interprets this pattern as consistent with Merton's (1968) social structure and anomie paradigm. Also surprisingly, Messner makes no attempt in his more recent study of SMSAs to explain why Merton's paradigm "works" for income inequality and homicides at the international level but does not work for this country.

2. Blau and Blau (1982) do consider simultaneously percentage of poverty and income inequality in examining 1970 homicide rates for SMSAs (see their Table 1) but they fail to introduce important etiological factors as control variables in this analysis. Accordingly, it is not possible to determine from their study whether either (or both) of these forms of deprivation is an important contributor to homicides.

3. To illustrate with the variable of primary concern here, the average murder rate for SMSAs in 1970 (7.10) does not reflect well the nature of homicide in the inner city $(\overline{\mathrm{X}}=12.12)$ nor in surrounding suburban areas $(\overline{\mathrm{X}}=3.80)$, and this is no less the case with the other variables in the Messner study.

4. Of note, Gibbs and Erickson (1976) argue that if cities (rather than SMSAs) are to be used as units of analysis in studies of crime, the ratio of the community (SMSA)-to-city population must be considered as a control variable as the number of potential participants in city crime (both as victims and offenders) is larger than the number of city residents, which is the denominator of conventional crime rates. To take this possibility into account, the proportion of the SMSA population residing in the city was considered in the analysis (Tables 1-4) as a control variable. Homicide rates for all three years proved to be unrelated to this population ratio. Accordingly, I excluded this variable from consideration in the findings reported in the next section of the paper. 
5. I chose to "operationally" consider large cities as those with a 1970 population of 100,000 or more. There is nothing sacred about the 100,000 population cutting point, but its choice does make theoretical and methodological sense. First, FBI statistics show a somewhat qualitative increase in homicides for cities over 100,000 population compared to smaller jurisdictions; second, the required homicide and sociodemographic data for the two earlier years (1950 and 1960) to be considered are more available for cities that had reached at least 100,000 population by 1970 .

6. Due to space limitations it is not possible to present the correlation matrices for the homicide and predictor variables for the three years. These data are available in tabular form, however, upon request from the author.

7. This is probably because the low-income factor was an afterthought of Messner's in trying to account for the negative findings for the poverty variable.

8. For the reasons discussed above, the low-income measure considered here (Table 4) may not be a good surrogate for a formal poverty measure like the Social Security Administration's, which takes into account important factors such as family income, family size, head of household status, regional variation in cost of living, and farm-nonfarm residence status.

\section{REFERENCES}

ALLEN, H. and W. BANKSTRON (1981) "Another look at the southern culture of violence hypothesis: the case of Louisiana." Southern Studies 20 (Spring): $55-66$.

ALLEN, H., D. McSEVENEY, and W. BANKSTRON (1981) "The influence of southern culture on race-specific homicide rates." Southern Spectrum 1 (October/December): 361-374.

BANFIELD, E. (1974) The Unheavenly City Revisited. Boston: Little, Brown.

- - (1968) The Unheavenly City. Boston: Little, Brown.

BENSING, R. and O. SCHROEDER (1960) Homicide in an Urban Community. Springfield, IL: Charles C. Thomas.

BLAU, J. and P. BLAU (1982) “The cost of inequality: metropolitan structure and violent crime." Amer. Soc. Rev. 47 (February): 114-127.

BLOCK, R. (1977) Violent Crime: Environment, Interaction and Death. Lexington, MA: Lexington Books.

BOGGS, S. (1965) "Urban crime patterns." Amer. Soc. Rev. 39 (December): 899-908.

BONGER, W. (1916) Criminality and Economic Conditions. Boston: Little, Brown.

BREARLEY, H. (1932) Homicide in the United States. Chapel Hill: Univ. of North Carolina Press.

BULLOCK, H. (1955) "Urban homicide in theory and fact." J. of Criminal Law, Criminology and Police Sci. 45 (January/February): 565-575.

CHAMBLISS, W. and D. SEIDMAN (1982) Law, Order and Power. Reading, MA: Addison-Wesley.

CLINARD, M. [ed.] (1964) Anomie and Deviant Behavior: A Discussion and Critique. New York: Free Press. 
CLOWARD, R. and L. OHLIN (1960) Delinquency and Opportunity: A Theory of Delinquent Gangs. New York: Free Press.

COHEN, A. (1955) Delinquent Boys. New York: Free Press.

COSER, L. (1963) "Violence and the social structure," pp. 30-42 in J. Masserman (ed.) Science and Psychoanalysis, Vol. 6. New York: Grune and Stratton.

CURTIS, L. (1974) Criminal Violence. Lexington, MA: D.C. Heath.

EBERTS, P. and K. SCHWIRIAN (1968) "Metropolitan crime rates and relative deprivation." Criminologica 5 (February): 43-52.

ENGLES, F. (1968) The Condition of the Working Class in England (W. B. Henderson and W. H. Chaloner, trans. ed.). Palo Alto, CA: Stanford Univ. Press.

Federal Bureau of Investigation (1971) Crime in the United States: Uniform Crime Reports, 1970. Washington, DC: Government Printing Office.

FERDINAND, T. (1970) "Demographic shifts and criminality." British J. of Criminology 10, 2: 169-175.

FRANKLIN, J. (1956) The Militant South: 1800-1961. Cambridge, MA: Harvard Univ. Press.

GASTIL, R. (1971) “Homicide and a regional culture of violence.” Amer. Soc. Rev. 36 (June): 412-427.

GIBBS, J. and M. ERICKSON (1976) "Crime rates in American cities in an ecological context." 82, 3: 605-620.

GORDON, D. (1971) "Class and economics of crime." Rev. of Radical Pol. Economy 3 (Summer): 51-75.

HACKNEY, S. (1969) "Southern violence," pp. 505-527 in H. Graham and T. Gurr (eds.) The History of Violence in America. New York: Bantam Books.

HENRY, A. and J. SHORT (1954) Suicide and Homicide: Some Economic, Sociological and Psychological Aspects of Aggression. New York: Free Press.

HUMPHRIES, D. and D. WALLACE (1980) “Capitalist accumulation and urban crime, 1950-1971." Social Problems 28 (December): 179-193.

JACOBSON, A. (1975) "Crime trends in southern and nonsouthern cities: a twenty-year perspective." Social Forces 54 (September): 226-242.

KREISBERG, B. (1975) Crime and Privilege: Toward a New Criminology. Englewood Cliffs, NJ: Prentice-Hall.

LOFTIN, C. and R. HILL (1974) "Regional subculture and homicide: an examination of the Gastil-Hackney thesis." Amer. Soc. Rev. 39 (October): 714-724.

LUCKINBILL, D. (1977) "Criminal homicide as a situated transaction." Social Problems 25 (December): 176-186.

LUNDSGAURDE, H. (1977) Murder in Space City. New York: Oxford Univ. Press.

MacDONALD, J. (1961) The Murderer and His Victim. Springfield, IL: Charles C Thomas.

MAGURA (1975) "Is there a subculture of violence?" Amer. Soc. Rev. 40 (December): 831-836.

MAYHEW, B. and R. LEVINGER (1976) 'Size and the density of interaction in human aggregates." Amer. J. of Sociology 82, 1: 87-110.

McCARTHEY, J., O. GALLE, and W. ZIMMERN (1975) "Population density, social structure and interpersonal violence: an intermetropolitan test of competing models." Amer. Behavioral Scientist 18 (July/August): 771-791. 
MERTON, R. (1968) Social Theory and Social Structure. New York: Free Press. - - (1938) "Social structure and anomie." Amer. Soc. Rev. 3 (October): 672-682.

MESSNER, S. (1982) "Poverty, inequality, and the urban homicide rate: some unexpected findings." Criminology 20 (May): 103-114.

(1980) "Income inequality and murder rates: some cross-national findings," pp. 185-198 in R. Tomasson (ed.) Comparative Social Research, Vol. 3. Greenwich CT: Jai Press.

MILLER, (1958) "Lower class culture as a generating milieu of gang delinquency." J. of Social Issues 14: 5-19.

OTT, L. (1977) Introduction to Statistical Methods and Data Analysis. Boston: Duxbury.

PARKER, R. and D.SMITH (1979) “Deterrence, poverty, and type of homicide." Amer. J. of Sociology 85 (November): 614-624.

POKORNY, A. (1965) "A comparison of homicides in two cities." J. of Criminal Law, Criminology and Police Sei. 56 (December): 479-486.

President's Commission on Law Enforcement and the Administration of Justice (1967) Task Force Report: Crime and its Impact-An Assessment. Washington, DC: Government Printing Office.

QUINNEY, R. (1980) Class, State and Crime. New York: Longman.

- - (1975) Criminology: Analysis and Critique of Crime in America. Boston: Little, Brown.

-- (1974) Criminal Justice in America. Boston: Little, Brown.

(1970) The Social Reality of Crime. Boston: Little, Brown.

(1966) "Structural characteristics, population areas, and crime rates in the United States." J. of Criminal Law, Criminology and Police Sci. 57, 1: 45-52.

REASONS, C. and R. RICH (1978) The Sociology of Law: A Conflict Perspective. Toronto: Butterworths.

SAGI, P. and C. WELLFORD (1968) "Age composition and patterns of change in criminal statistics." J. of Criminal Law, Criminology and Police Sci. 59, 1: 29-35.

SCHMID, C. (1960) "Urban crime areas: part I." Amer. Soc. Rev. 25 (August): 527-542.

SCHUSSLER, K. (1961-1962) "Components of variation in city crime rates." Social Problems 9 (Spring): 314-323.

- - and G. SLATIN (1964) "Sources of variation in U.S. city crime, 1950 and 1960." J. of Research in Crime and Delinquency 1 (July): 127-148.

SHAW, C. and H. McKAY (1942) Juvenile Delinquency and Urban Areas. Chicago: Univ. of Chicago Press.

SIMMEL, G. (1903) "Die Grossstädte und das Geistesleben," pp. 185-206 in T. Peterman (ed.) Die Grossstadt. Dresden: Zahn and Jaensch.

SMITH, M. and R. PARKER (1980) "Type of homicide and variation in regional rates." Social Forces 59 (September): 136-147.

TAYLOR, I., P. WALTON, and J. YOUNG (1973) The New Criminology. London: Routledge Kegan Paul.

WELLFORD, C. (1973) "Age composition and the increase in crime." Criminology 11 (May): 61-70. 
WIR'TH, L. (1938) "Urbanism as a way of life." Amer. J. of Sociology 44 (July): 1-24.

WOLFGANG, M. (1958) Patterns of Criminal Homicide. Philadelphia: Univ. of Pennsylvania Press.

- - and F. FERRACUTI (1967) The Subculture of Violence. London: Tavistock.

Post-print standardized by MSL Academic Endeavors, the imprint of the Michael Schwartz Library at Cleveland State University, 2014 